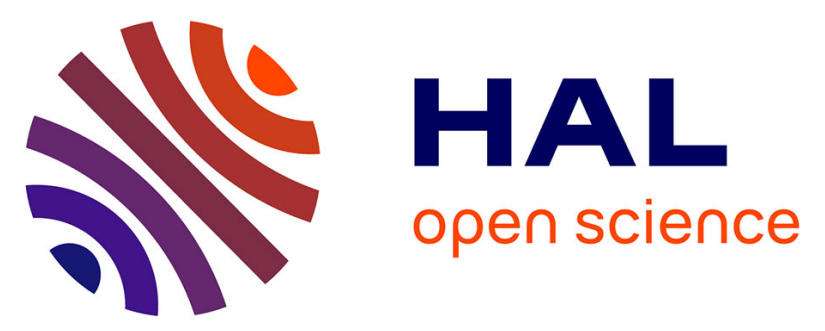

\title{
Influence of the solar wind dynamic pressure on the ion precipitation: MAVEN observations and simulation results
}

Antoine Martinez, Ronan Modolo, François Leblanc, Jean-Yves Chaufray, Olivier Witasse, N. Romanelli, Y. Dong, T. Hara, J. Halekas, R. Lillis, et al.

\section{To cite this version:}

Antoine Martinez, Ronan Modolo, François Leblanc, Jean-Yves Chaufray, Olivier Witasse, et al.. Influence of the solar wind dynamic pressure on the ion precipitation: MAVEN observations and simulation results. Journal of Geophysical Research Space Physics, 2020, 125 (10), pp.e2020JA028183. 10.1029/2020JA028183 . insu-02950993

\section{HAL Id: insu-02950993 https://hal-insu.archives-ouvertes.fr/insu-02950993}

Submitted on 16 Dec 2020

HAL is a multi-disciplinary open access archive for the deposit and dissemination of scientific research documents, whether they are published or not. The documents may come from teaching and research institutions in France or abroad, or from public or private research centers.
L'archive ouverte pluridisciplinaire HAL, est destinée au dépôt et à la diffusion de documents scientifiques de niveau recherche, publiés ou non, émanant des établissements d'enseignement et de recherche français ou étrangers, des laboratoires publics ou privés. 


\section{Influence of the solar wind dynamic pressure on the ion}

\section{2 precipitation: MAVEN observations and simulation results.} .

A. Martinez ${ }^{1}$, R. Modolo ${ }^{2}$, F. Leblanc ${ }^{1}$, J. Y. Chaufray ${ }^{1,2}$, O. Witasse ${ }^{3}$, N. Romanelli ${ }^{4}$, Y. Dong ${ }^{5}$, T. Hara ${ }^{6}$,

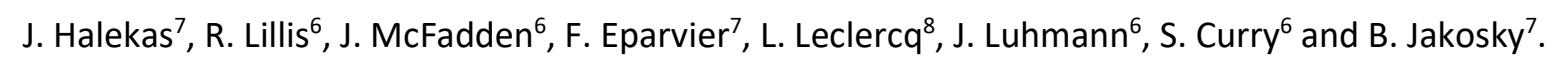

${ }^{1}$ LATMOS/IPSL Sorbonne Université, UVSQ, CNRS, Paris, France

${ }^{2}$ LATMOS/IPSL, UVSQ Université Paris-Saclay, Sorbonne Université, CNRS, Guyancourt, France . ${ }^{3}$ ESTEC, European Space Agency, Noordwijk, Netherlands

${ }^{4}$ Solar System Exploration Division, NASA Goddard Space Flight Center, Greenbelt, MD, USA. CRESST II, University of Maryland, Baltimore County, Baltimore, MD, USA.

\footnotetext{
${ }^{5}$ Laboratory for Atmospheric and Space Physics, University of Colorado, Boulder, CO, USA
}

${ }^{6}$ Space Science Laboratory, University of California, Berkeley, CA, USA

${ }^{7}$ Department of Physics and Astronomy, University of lowa, IA, USA

${ }^{8}$ University of Virginia, Charlottesville, VA 22904, USA. 


\section{Abstract:}

Using the data from the SWIA and STATIC instruments on board Mars Atmosphere and Volatile EvolutioN (MAVEN) and LatHyS (Latmos Hybrid Simulation) simulations, we investigate the heavy ion precipitation into the Martian atmosphere. We discuss the influence of the solar wind dynamic pressure on the ion precipitation using observations performed by MAVEN from 04 June 2014 to 20 July 2017. The increase of the dynamic pressure from 0.63 to $1.44 \mathrm{nPa}$ is clearly associated with an increase of the same order of magnitude of the precipitating oxygen ion energy flux measured by MAVEN/STATIC from 9.9 to $20.6 \times 10^{6} \mathrm{eV} \cdot \mathrm{cm}^{-2} \cdot \mathrm{sr}^{-1} \cdot \mathrm{s}^{-1}$ at low energy (from 30 to $650 \mathrm{eV}$ ). In the same way, from $650 \mathrm{eV}$ to $25000 \mathrm{eV}$, MAVEN/SWIA (all species) observed an increase from 22.4 to $42.8 \times 10^{7} \mathrm{eV} \cdot \mathrm{cm}^{-2} \cdot \mathrm{sr}^{-1} \cdot \mathrm{s}^{-1}$ of the precipitating ion energy flux.

Performing two simulations using the average solar wind conditions for both solar dynamic pressure regimes observed by MAVEN as input in the LatHyS model, we reproduce some of the key characteristics of the observed oxygen ion precipitation. We characterize the oxygen ions simulated by LatHyS by their energy and time of impact, their time of injection in the simulation and initial position and the mechanism by which these ions were created. The model suggests that the main cause of the increase of the heavy ion precipitation during an increase of the solar dynamic pressure is the increase of the ion production by charge exchange, proportional to the increase of the solar wind flux, which becomes the main contribution to the ion precipitation at high energy. 
In the absence of a global magnetic field, Mars' upper atmosphere interacts directly with the solar wind. Planetary neutral species (mainly carbon dioxide molecules, hydrogen and oxygen atoms) are ionized by photoionization, electronic impact or charge exchange and are accelerated by the motional electric field of the solar wind. These charged particles can precipitate into Mars' atmosphere with energy up to several keV and induce a cascade of collisions, transferring enough energy to atmospheric particles to exceed the Martian escape velocity (Luhmann and Kozyra, 1991; Johnson, 1994). While this process, named atmospheric sputtering, may have led to significant atmospheric escape in its early history, as suggested by Luhmann et al. (1992), its contribution is nowadays minor compared to other neutral escape processes like Jeans escape (Anderson and Hord, 1971; Krasnopolsky and Feldman, 2001) and photochemical escape (Lillis et al., 2015; 2017), or ion escape process like pick-up ions (Luhmann, 1990; Fang et al., 2010; Dong et al., 2017) and ion outflow (Lundin et al., 1990; Andersson et al., 2010).

Atmospheric escape induced by sputtering at the present epoch is expected to be small compared to other mechanisms (Leblanc et al. 2017) and therefore difficult to quantify from direct measurements. However, since heavy planetary ion precipitation (which we define as having mass larger or equal to the mass of carbon atom) is the primary driver of atmospheric sputtering (Johnson et al, 2000; Wang et al, 2014; 2015), it is essential to constrain the dependence of the precipitating ion flux on present solar wind conditions in order to, potentially, extrapolate the effect of this mechanism, over the Martian history. In situ measurements of precipitating ions began with Mars Express (MEX) spacecraft, in orbit around Mars since December 2003, (e.g., Chicarro et al., 2004; Barabash et al., 2006). Hara et al. (2011) reported that MEX observed enhancements of precipitating heavy ions (e.g. $O^{+}$and $O_{2}^{+}$) during the passage of Corotating Interaction Region (CIR) solar wind structures. This observation suggests that heavy ion precipitation is highly variable and depends on the upstream solar wind 
conditions at Mars. Thanks to Mars Atmosphere and Volatile EvolutioN (MAVEN) measurements, observations of heavy ion precipitation during quiet solar wind conditions have been reported by Leblanc et al. (2015), suggesting that atmospheric sputtering occurs almost continuously at Mars.

Several investigations, either from observational or modeling studies, have highlighted the influence of the plasma properties on the Martian environment. Edberg et al. (2009), Hall et al. (2016), Halekas et al. (2017) and Ramstad et al. (2017) have shown that the solar EUV irradiance and the solar wind dynamic pressure have an influence on the position of plasma boundaries such as the Magnetic Pileup Boundary (MPB) and the Bow Shock (BS). Indeed, the newly created exospheric ions can act to slow the solar wind flux, which can move the bow shock position away from the planet (Hall et al, 2016). Moreover, Lundin et al. (2008) also showed that the size of the Martian obstacle (estimated as proportional to the BS position) influences the ion atmospheric escape rate.

The statistical study by Hara et al. (2017a) has showed that precipitating ion fluxes observed by MAVEN (Jakosky et al., 2015) vary at least by an order of magnitude (typically between $10^{4} \mathrm{~cm}^{-2} \cdot \mathrm{s}^{-1} \mathrm{sr}^{-1}$ and $10^{6} \mathrm{~cm}^{-2} \cdot \mathrm{s}^{-1} \mathrm{sr}^{-1}$ for ions with energies higher than $25 \mathrm{eV}$ ) depending on the upstream solar wind conditions such as the dynamic pressure, the magnitude of the interplanetary magnetic field, and the motional electric field direction $\vec{E}=-\vec{V}_{S W} \times \vec{B}_{S W}$ with $\vec{V}_{S W}$ the solar wind velocity and $\vec{B}_{S W}$ the interplanetary magnetic field vector. Indeed, it has been shown by several theoretical studies (Luhmann and Kozyra 1991; Chaufray et al. 2007; Curry et al. 2015) that the orientation of the motional electric field may influence the energy and intensity of ion precipitation on Mars. These studies suggested that the integrated total precipitating ion fluxes are globally larger in the $-\vec{E}$ hemisphere than in the $+\vec{E}$ hemisphere. Pickup oxygen ions formed in the $-\vec{E}$ hemisphere are accelerated towards Mars and can precipitate while oxygen ions formed in the $+\vec{E}$ hemisphere are accelerated away from Mars and can escape. Such results have been observed by Martinez et al. (2019a) and Hara et al. (2017a) thanks to MAVEN. 
Curry et al. (2015) have studied the response of Mars $0^{+}$pickup ions to an ICME (March $8^{\text {th }}, 2015$ ) with a test-particle approach and found that the oxygen ion precipitation depends on the phase of the ICME with a maximum of precipitation during the shock. After the passage of the ICME shock, the precipitating flux of the ejecta phase decreases but still remains greater than the precipitating flux during the pre-ICME phase. Based on a similar approach, Fang et al. (2013) have shown that oxygen ion precipitation can vary by at least one order of magnitude due to the variation in dynamic pressure during ICME or CIR solar wind events. Similar conclusions have been reported by Hara et al. (2011) with Mars Express observation or by Martinez et al. (2019a) with MAVEN observations during the September 2017 solar events (Lee et al. 2018).

Complementary to observations, models can provide an extended set of information to better characterize the physical processes under investigations. By being able to take into account a wide variety of physical processes in time and space, models can be used to reproduce observations and investigate the resulting mechanisms. They provide a three-dimensional context for the observations. At the beginning of Martian exploration, with Mariner 4 or Phobos 2, computer simulations have been found very useful for investigating the physic mechanisms of the atmospheric escape (Luhmann and Kozyra, 1991; Luhmann, Jonhson \& Zhang, 1992; Johnson, 1994; Leblanc \& Johnson, 2001; 2002; Dubinin \& Lundin, 1995; Fang et al., 2010). Some studies also make it possible to model the present and past contributions of these mechanisms to atmospheric escape (Chassefière \& Leblanc, 2004). Combining MEX observations and sophisticated global model simulations, Diéval et al. (2012) have shown that the precipitating protons originate from both the solar wind and the planetary exosphere. Here, we use model to simulate the potential effects of the solar dynamic pressure on the ion precipitation.

In this paper, we further analyze the role of the solar dynamic pressure on the ion precipitation by performing a detailed analysis of MAVEN measurements combined with the simulation of its potential effects. The LATMOS Hybrid Simulation (LatHyS) model (Modolo et al, 2016) is used to constrain the processes that may control the ion precipitation. The instruments and data used to perform this 


\section{II. MAVEN measurements of the solar wind conditions and precipitating ion flux}

analysis, as well as the methodology developed are described in section II. The model is described in section III whereas section IV present the main results and lessons derived from the simulation/measurement comparisons and section $\mathrm{V}$ the conclusions.

\section{A. Instruments and Data}

The large set of MAVEN instruments (Jakosky et al. 2015) allows us to characterize the precipitating ion flux as well as the upstream solar wind conditions and also to constrain the atmospheric and plasma properties of the Martian environment. In this study, we use measurements performed by the Solar Wind Ion Analyzer (SWIA; Halekas et al., 2015), the SupraThermal and Thermal lon Composition (STATIC; McFadden et al., 2015), the Magnetometer (MAG; Connerney et al., 2015a; 2015b) and the Solar Extreme Ultraviolet Monitor (EUVM; Eparvier et al., 2015). The MAVEN/SWIA instrument is an energy and angular ion spectrometer. In this work, we use the SWIA coarse survey data product, covering an energy range between $25 \mathrm{eV} / \mathrm{q}$ and $25 \mathrm{keV} / \mathrm{q}$ with 48 energy steps logarithmically spaced, a field of view (FOV) of $360^{\circ} \times 90^{\circ}$ with 64 angular bins and $4 \mathrm{~s}$ time resolution. The MAVEN/STATIC instrument is an energy, mass and angular ion spectrometer. We used the STATIC "D1" data product, covering an energy range between $0.1 \mathrm{eV} / \mathrm{q}$ and $35 \mathrm{keV} / \mathrm{q}$ with 32 energy steps logarithmically spaced, a field of view (FOV) of $360^{\circ} \times 90^{\circ}$ on 64 angular bins and 8 mass bins covering a mass range from 1 amu to 80 amu with a 4 s time resolution.

We mainly based our study on MAVEN/SWIA despite the lack of mass resolution because MAVEN/STATIC operates mostly in conic mode (McFadden et al. 2015) below $350 \mathrm{~km}$ in altitude leading to a limited coverage for ions with energy larger than $650 \mathrm{eV}$. In the following, we use MAVEN/STATIC to refine our analysis for energies below $650 \mathrm{eV}$. Moreover, in order to avoid any potential bias in the measurement due to spacecraft charging, we only consider precipitating ions with energies larger than $30 \mathrm{eV}$. Although MAVEN/SWIA does not have mass resolution, it can be used to estimate the evolution of heavy ion precipitation for the high energy range. Pickup ions can be 
accelerated by the motional electric field up to a maximum energy limit (Jarvinen and Kallio, 2014; Rahmati et al., 2015) which is:

$$
E_{\max }\left(M^{+}\right)=4 * m_{M} * U_{S W}^{2} * \sin ^{2}\left(\theta_{U B}\right)=4 * E_{S W} *\left(\frac{m_{M}}{m_{p}}\right) * \sin ^{2}\left(\theta_{U B}\right)
$$

Where $\mathrm{M}^{+}$is the species with a mass $m_{M}$ and $\theta_{U B}$ is the angle between the solar wind velocity and the interplanetary magnetic field, $m_{p}$ is the proton mass and $E_{S W}$ is the energy of the solar wind proton. The maximum energy is 4 times that of the solar wind, that is, typically around four times $800 \mathrm{eV}$ to 1 $\mathrm{keV}$ for nominal conditions for planetary protons and four times $2.4 \mathrm{keV}$ to $4 \mathrm{keV}$ for planetary helium ions. Therefore, any ions precipitating with energy larger than few keV are most probably planetary ions with masses larger than the proton and helium masses.

The MAVEN/EUVM measures the solar irradiance in three bands from the soft X-ray to the EUV range (in three spectral bands $0.1-7 \mathrm{~nm}, 17-22 \mathrm{~nm}$ and $121-122 \mathrm{~nm}$ ) with a temporal resolution of $1 \mathrm{~s}$. To characterize the solar EUV irradiance, we use MAVEN/EUVM channel A which measures solar irradiance between 17 and $22 \mathrm{~nm}$.

The solar wind density, solar wind velocity, and Interplanetary Magnetic Field (IMF) vectors are measured by MAVEN/SWIA and MAVEN/MAG and averaged on an orbit-by-orbit basis while MAVEN is in the pristine solar wind (Halekas et al., 2017). In this work, we use the Mars Solar Electric (MSE) coordinate system in which the X-axis points toward the Sun, the Z-axis is aligned with the solar wind motional electric field and the $\mathrm{Y}$-axis completes the right hand system (Fedorov et al., 2006).

\section{B. Upstream and planetary conditions}

To investigate the dependence of the precipitating ion flux with respect to the solar wind dynamic pressure, we used the method developed by Dong et al. (2017) and Martinez et al. (2019b). In absence of permanent solar wind monitoring, we assume that the averaged solar wind parameters, measured by MAVEN when inside the solar wind, are constant during the whole orbit as explained in Martinez et 

al. (2019b). Solar wind parameters on an orbit-by-orbit basis, when MAVEN was in the solar wind, are then used to determine the average solar wind parameters for a given set of measurements.

We organize MAVEN data into two sets of measurements corresponding to two different solar wind dynamic pressure conditions: a low dynamic pressure case with values between 0.3 and $1.0 \mathrm{nPa}$ and a high dynamic pressure case with values between 1.0 and $2.6 \mathrm{nPa}$. The IMF strength $\left(B_{I M F}\right)$ is also imposed between 2.2 and $6.7 \mathrm{nT}$. The solar wind dynamic pressure is defined as $P_{d y n}=m_{p} n_{S W} V_{S W}^{2}$, where $m_{p}$ is the mass of the proton, $n_{S W}$ and $V_{s w}$ the solar wind density and velocity. For both sets of measurements, we determine the mean solar wind conditions and calculate the norm of the solar wind motional electric field defined as $E=\left|\overrightarrow{V_{S W}} \times \overrightarrow{B_{I M F}}\right|$, the solar wind particle flux defined as $F_{S W}=$ $n_{S W} V_{S W}$, the Alfven Mach number defined as $M_{A}=\frac{V_{S W}}{V_{A}}$ (with the $V_{A}$ the Alfvén speed), the magnetosonic Mach number $M_{M S}$ as defined in Edberg et al., (2010) and the MSE angle as defined in Martinez et al., (2019a). The MSE angle corresponds to the anticlockwise angle between the MAVEN's location in MSE coordinates during it measurements of the precipitating ion flux and the East MSE direction (MSE longitude equal to $+180^{\circ}$ and latitude equal to $0^{\circ}$ ).

These parameters are displayed in Table 1 . The last column of Table 1 presents the coverage distribution, as defined in Martinez et al, (2019b), showing the percentage of common distribution for a given parameter between the two dynamic pressure groups. Except for the solar wind density and flux, and obviously for the dynamic pressure, all solar wind properties show similar variations with about $70 \%$, or more, of the distribution of each of these parameters in common. In other words, the EUV irradiance, IMF intensity, Alfven and magnetosonic Mach numbers, solar wind speed and MSE angle are similar during these two set of measurements. The spatial coverage of the ion precipitation measurements, characterized by the MSE angle and the solar zenith angle, is also similar during these two set of measurements. 
188 the precipitating ion flux, as shown by Hara et al. (2017b). In order to limit the potential influence of

189 the crustal fields (Leblanc et al. 2017; Hara et al. 2017b), we also only consider measurements

190 performed when the average magnetic field between 200 and $350 \mathrm{~km}$ was less than $60 \mathrm{nT}$. Moreover,

191 to further limit the potential role of the crustal fields on the precipitation, we also consider only

192 MAVEN measurements performed when the main crustal field region (centered at $180^{\circ}$ GEO East

193 longitude and $-50^{\circ}$ GEO latitude) was in the nightside, meaning when the subsolar point has a GEO

194 longitude from $-60^{\circ}$ to $60^{\circ}$.

195

\begin{tabular}{|c|c|c|c|c|}
\hline & & $\begin{array}{l}\text { High Pdyn } \\
{[1.0,2.6] \mathrm{nPa}}\end{array}$ & $\begin{array}{c}\text { Low Pdyn } \\
{[0.3,1.0] \mathrm{nPa}}\end{array}$ & $\begin{array}{c}\text { Common } \\
\text { coverage (\%) }\end{array}$ \\
\hline \multirow{3}{*}{$\begin{array}{l}\text { EUV Flux } \\
\left(\boldsymbol{m W} \cdot \boldsymbol{m}^{-2}\right)\end{array}$} & $\mu \pm \sigma$ & $0.22 \pm 0.04$ & $0.22 \pm 0.03$ & \multirow{3}{*}{85.5} \\
\hline & Q25 & 0.19 & 0.20 & \\
\hline & Q75 & 0.24 & 0.23 & \\
\hline \multirow{3}{*}{$\begin{array}{c}\text { Dynamic } \\
\text { pressure } \\
(\boldsymbol{n P a})\end{array}$} & $\mu \pm \sigma$ & $1.44 \pm 0.41$ & $0.63 \pm 0.19$ & \multirow{3}{*}{0.0} \\
\hline & Q25 & 1.13 & 0.46 & \\
\hline & Q75 & 1.63 & 0.79 & \\
\hline \multirow{3}{*}{$\begin{array}{l}\text { Solar Zenith } \\
\text { Angle }\left({ }^{\circ}\right)\end{array}$} & $\mu \pm \sigma$ & $96 \pm 28$ & $96 \pm 28$ & \multirow{3}{*}{89.7} \\
\hline & Q25 & 80 & 77 & \\
\hline & Q75 & 115 & 118 & \\
\hline \multirow{3}{*}{$\begin{array}{l}\text { Electric field } \\
\left(\boldsymbol{m} V \cdot \boldsymbol{m}^{-1}\right)\end{array}$} & $\mu \pm \sigma$ & $1.44 \pm 0.55$ & $1.04 \pm 0.45$ & \multirow{3}{*}{68.6} \\
\hline & Q25 & 1.00 & 0.74 & \\
\hline & Q75 & 1.77 & 1.20 & \\
\hline \multirow{3}{*}{$\begin{array}{l}\text { IMF } \\
(n T)\end{array}$} & $\mu \pm \sigma$ & $3.90 \pm 1.12$ & $3.23 \pm 0.95$ & \multirow{3}{*}{69.1} \\
\hline & Q25 & 2.92 & 2.50 & \\
\hline & Q75 & 4.52 & 3.60 & \\
\hline \multirow{3}{*}{$\begin{array}{c}\text { Speed } \\
\left(\mathrm{km} \cdot \mathrm{s}^{-1}\right)\end{array}$} & $\mu \pm \sigma$ & $448 \pm 80$ & $423 \pm 78$ & \multirow{3}{*}{80.1} \\
\hline & Q25 & 376 & 370 & \\
\hline & Q75 & 495 & 467 & \\
\hline \multirow{3}{*}{$\begin{array}{l}\text { Density } \\
\left(\mathrm{cm}^{-3}\right)\end{array}$} & $\mu \pm \sigma$ & $4.67 \pm 1.93$ & $2.25 \pm 0.97$ & \multirow{3}{*}{40.9} \\
\hline & Q25 & 3.28 & 1.49 & \\
\hline & Q75 & 5.69 & 2.78 & \\
\hline \multirow{2}{*}{ MSE angle $\left({ }^{\circ}\right)$} & $\mu \pm \sigma$ & $178 \pm 110$ & $203 \pm 110$ & \multirow{2}{*}{86.2} \\
\hline & Q25 & 94.7 & 153 & \\
\hline
\end{tabular}




\begin{tabular}{|c|c|c|c|c|}
\hline & Q75 & 263 & 322 & \\
\hline \multirow{3}{*}{$\begin{array}{c}\text { Alfven Mach } \\
\text { number }\end{array}$} & $\mu \pm \sigma$ & $11.5 \pm 3.0$ & $9.1 \pm 2.5$ & \multirow{3}{*}{68.9} \\
\hline & Q25 & 9.3 & 7.3 & \\
\hline & Q75 & 13.1 & 10.8 & \\
\hline \multirow{3}{*}{$\begin{array}{l}\text { Magnetosonic } \\
\text { Mach number }\end{array}$} & $\mu \pm \sigma$ & $7.76 \pm 1.36$ & $7.10 \pm 1.38$ & \multirow{3}{*}{86.4} \\
\hline & Q25 & 6.83 & 6.10 & \\
\hline & Q75 & 8.58 & 8.07 & \\
\hline \multirow{3}{*}{$\begin{array}{l}\text { Solar wind flux } \\
\left(10^{8} \mathrm{~cm}^{-2} s^{-1}\right)\end{array}$} & $\mu \pm \sigma$ & $1.98 \pm 0.62$ & $0.91 \pm 0.29$ & \multirow{3}{*}{23.5} \\
\hline & Q25 & 1.57 & 0.68 & \\
\hline & Q75 & 2.36 & 1.09 & \\
\hline
\end{tabular}

Table 1: Mean $\mu$, standard deviation $\sigma$, first quartile Q25 and third quartile Q75 of the solar zenith angle and each solar planetary parameter distribution for the two sets of precipitating flux measurement. The last column provides the percentage of the area in common between the two distributions.

\section{MAVEN's ion precipitation measurements}

In order to reconstruct the precipitating ion energy flux, we use the method developed by Leblanc et al. (2015) and Martinez et al (2019a). We use MAVEN observations of the two sets of measurements performed between 200 and $350 \mathrm{~km}$. Within such altitude range, any ions moving toward the planet in a cone of less than $75^{\circ}$ with respect to the local nadir direction has a very large probability to impact Mars' atmosphere. Therefore, to reconstruct the precipitating flux, we sum all measurements of SWIA (and STATIC) anodes with a FOV corresponding to a cone of less than $75^{\circ}$ from the local zenith direction. Moreover, in order to exclude the reconstructed precipitating flux with poor coverage, we only consider measurements during which the total FOV of SWIA (and STATIC) anodes covers more than $65 \%$ of the $75^{\circ}$ solid angle cone centered on the zenith direction. In the case of MAVEN/SWIA measurements, which has a low signal-to-noise ratio at high energy, we adapted the method from Martinez et al. (2019a) to remove an average background induced by Solar Energetic Particles (SEP). 
Compared to MAVEN/SWIA, MAVEN/STATIC is less sensitive to SEPs because its measurements

technique is based on double coincidence (McFadden et al., 2015). In case of intense SEP events or

background level, STATIC measurements with poor quality were flagged and systematically excluded from our analysis. So, the background level of MAVEN/STATIC is assumed to be negligible.

In this study, MAVEN observations obtained from June $4^{\text {th }}, 2015$ to July $20^{\text {th }}, 2017$ have been categorized into two groups with similar spatial coverage: high dynamic pressure with $1.44 \mathrm{nPa}$ averaged on 226 ion precipitation spectra by MAVEN/SWIA, and low dynamic pressure with $0.63 \mathrm{nPa}$ averaged on 454 ion precipitation spectra by MAVEN/SWIA.

222

\section{III. LatHyS Model}

In order to simulate the Martian environment and the precipitating heavy ion flux, we choose to use the hybrid approach which describes ions with a kinetic approach while the electrons are treated as a fluid (Modolo et al. 2016). The hybrid model called LatHyS is a 3-D multispecies parallelized model that simulates the interaction of the solar wind plasma with the neutral environment of the planet, characterizing all plasma regions in the vicinity of the planet. A detailed description of the LatHyS model can be found in Modolo et al. (2005 and 2016). The model uses as inputs a 3-D density description of $\mathrm{H}, \mathrm{O}$ and $\mathrm{CO}_{2}$ representing the thermosphere and exosphere. The neutral species description is modeled from the LMD - Global Circulation Model (Forget et al, 1999; Chaufray et al. 2014) and the Exospheric Global Model (Yagi et al, 2012; Leblanc et al, 2017). The state of the neutral environment corresponds to solar longitude $L s=270^{\circ}$. The spatial resolution of the LatHyS results presented in this paper is $\Delta \mathrm{x}=57 \mathrm{~km}$, and a mean solar activity is assumed for all the models (LatHyS, EGM, LMD-GCM) and for the two solar wind dynamic pressure cases. 
Simulations are set up with typical solar wind parameters based on the orbit-by-orbit average solar wind parameters for the two groups of solar wind dynamic pressure, from Table 1. To facilitate the interpretation of the simulated precipitation fluxes, the interplanetary magnetic field is taken with only a $B_{y}$ component. For the period of high dynamic pressure we have: $n_{S W}=4.7 \mathrm{~cm}^{-3}, V_{S W}=$ $450 \mathrm{~km} \cdot \mathrm{s}^{-1}$ and $B_{y}=4.0 \mathrm{nT}$. For the period of low dynamic pressure we have: $n_{S W}=2.2 \mathrm{~cm}^{-3}$, $V_{S W}=424 \mathrm{~km} \cdot \mathrm{s}^{-1}$ and $B_{y}=3.2 \mathrm{nT}$. Simulations are performed with a sub-solar longitude at $0^{\circ}$ and a subsolar latitude at $-23^{\circ}$, meaning that the main crustal field region is located in the nightside. To further analyze simulation results, for each particle we record the information of the injection position, the ionization mechanism of the particle, the injection time, the precipitation time and its precipitating energy. Three main sources of ions are implemented in the simulation model. A simplified set of ionospheric chemistry equations is included (below $350 \mathrm{~km}$ ) and particles created in this region are labeled as ionospheric particles. Particles can also be produced by photo-ionization above $350 \mathrm{~km}$, where the optical depth is negligible, or undergo charge exchange reactions. Information concerning the ionization processes are detailed in Modolo et al. (2016).

In this study, we consider only oxygen ions. Heavier ions (such as $\mathrm{Ar}^{+}, \mathrm{O}_{2}^{+}$and $\mathrm{CO}_{2}^{+}$) are not considered because of their much lower density at high altitude according to Fox (2004) so that their contribution to atmospheric sputtering should be very limited in intensity. Once a steady state of the simulation is achieved, $\mathrm{O}^{+}$ion precipitating $\left(V_{r}<0\right)$ below $250 \mathrm{~km}$ in altitude are recorded in order to construct an energy flux map on a $4.5^{\circ} \times 4.5^{\circ}$ longitude-by-latitude grid. To have meaningful statistics on the precipitating $\mathrm{O}^{+}$ions, the accumulation is performed over 100 solar wind proton gyro-periods (about 6-7 transit times of the simulation box). Each energy spectra corresponding to the impacting $\mathrm{O}^{+}$flux is computed with an energy resolution of $\frac{d E}{E}=\sim 17 \%$ for energy larger than $2 \mathrm{eV}$. With more than one million precipitating numerical particles for each simulation, the modelled sample is large enough to be statistically significant. The stationarity of the solution has been checked by comparing energy 
spectra at each grid point of the map for various accumulation intervals. We found a temporal standard deviation of $15-20 \%$ indicating that the simulation converged to a stable solution.

In order to compare simulation and observation, a similar methodology to reconstruct the simulated precipitation as for MAVEN measurements have been used:

- For each sequence of observation, the portion of MAVEN trajectory during which the precipitating flux was measured (between $200 \mathrm{~km}$ and $350 \mathrm{~km}$ in altitude) is reconstructed in the simulated MSE reference frame.

- The simulated energy spectra of the precipitating flux along each of these portions of MAVEN trajectory are then reconstructed and averaged. If, for a given energy bin, the simulated flux is lower than the threshold corresponding to MAVEN/SWIA background, the simulated precipitated ion energy flux, for this energy bin, is not considered to calculate the average.

\section{LatHyS simulated precipitation and MAVEN precipitating measurements}

\section{A. Comparison between MAVEN observation of the precipitating flux and LatHyS simulated} $\underline{\text { flux }}$

Figure 1 shows the comparison of the spectrum of the average precipitating ion energy flux for MAVEN/SWIA, MAVEN/STATIC and as simulated for the two dynamic pressure cases. The energy dependence of the differential flux is similar from one solar wind dynamic pressure case to the other for both instruments. For both dynamic pressure cases, the low-energy component of the precipitating oxygen ion energy flux measured by MAVEN/STATIC and simulated follow similar dependency with higher fluxes for larger dynamic pressure. Below $50 \mathrm{eV}$, we notice an increasing discrepancy between observation and simulation. This difference can be, in part, explained by the limited resolution of the simulations $(57 \mathrm{~km})$. At low energy, the main component of the oxygen ion precipitation comes from the ionospheric region (below $350 \mathrm{~km}$ in altitude) where the spatial resolution of the simulation 
remains several times higher than the thermospheric height scale $(11-20 \mathrm{~km})$. Because of this, ion production in the ionosphere (below $350 \mathrm{~km}$ in altitude) is probably poorly described, making it less sensitive to any external variations.

For energy larger than a few keVs, as explained in section II.A, MAVEN/SWIA observed ion precipitation should be in large proportion composed of $\mathrm{O}^{+}$ions. Above 3 to $4 \mathrm{keV}$, there is a clear increase of the measured and simulated precipitating fluxes from the low dynamic pressure case to the high dynamic pressure case. The gap between the MAVEN/SWIA curves (all species) and those of the model (only oxygen ions) between $300 \mathrm{eV}$ and $3-4 \mathrm{keV}$ can be explained by the contribution of other species in the observed ion precipitation (mainly protons, in particular around the solar wind energy, probably produced in the hydrogen corona).

Table 2 shows the integrated precipitating ion energy flux for each dynamic pressure case and two energy ranges: low energy [30-650] eV) and high energy [650-25000] eV. The ion precipitation increases when the dynamic pressure of the solar wind increases, as previously observed by Hara et al. (2017a) with MAVEN/SWIA and MAVEN/STATIC measurements. It increases by a factor between 1.7 and 2.0 at low energy and by factor 1.9 to 2.1 at high energy. Both simulation and observation agree relatively well when comparing the two dynamic pressure cases, even if the simulation predicts a systematic factor $\sim 4$ lower integrated flux with respect to SWIA observed precipitation for both solar dynamic pressure cases and energy ranges. At high energy, this factor can be partially explained by the fact that the modelled precipitating ion energy flux becomes lower than the MAVEN/SWIA background and so, the energy ion flux is not considerate, which slightly underestimate the modelled ion precipitation. In other words, even if the simulation did not perfectly reproduce the absolute intensity of the observed precipitation, the simulated variation of the precipitating flux with increasing pressure might be driven by a similar mechanism to the one controlling the dependency of this flux in MAVEN observations. 


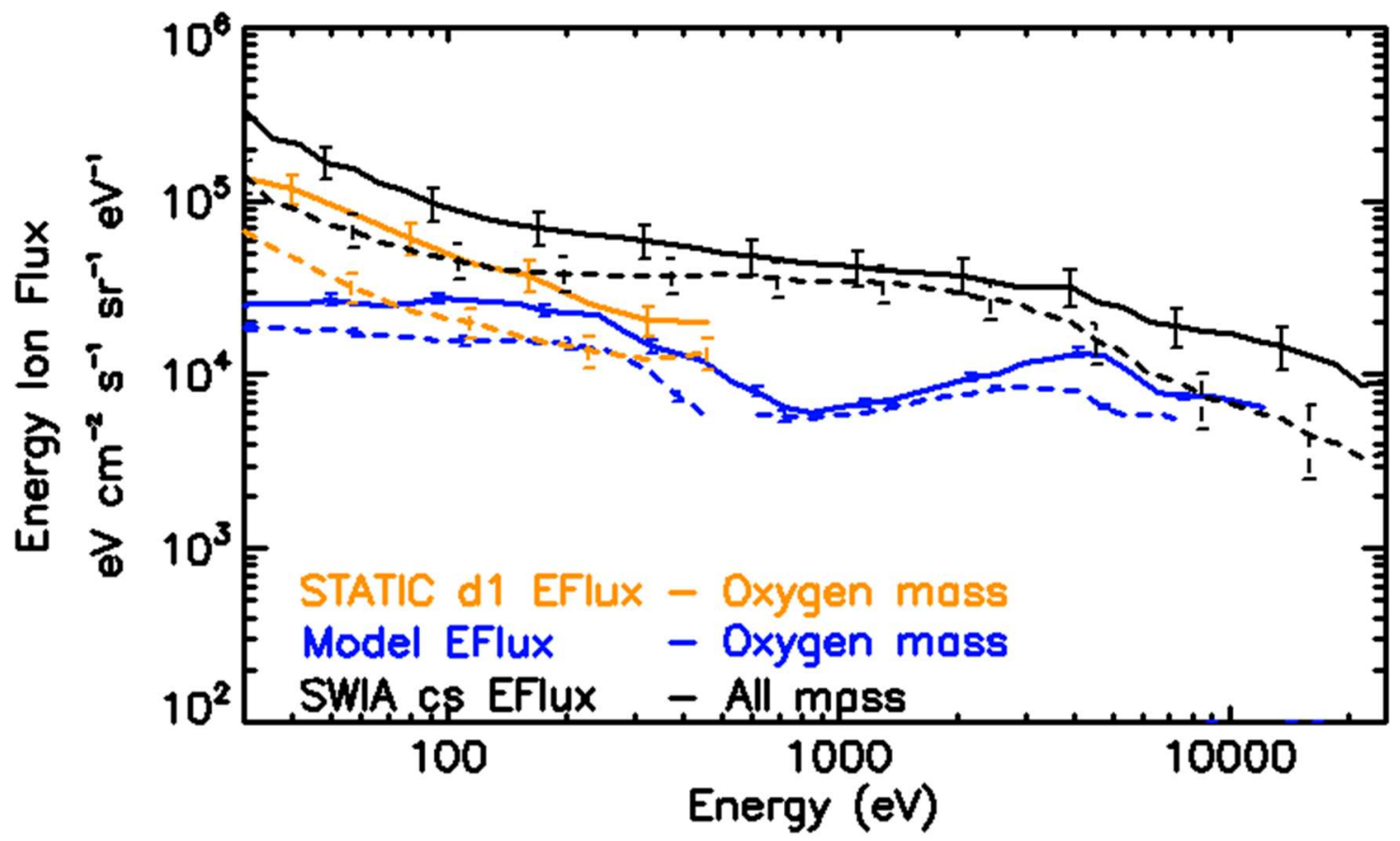

Figure 1: Average precipitating ion differential energy spectra as measured by MAVEN/SWIA

(black - all species), MAVEN/STATIC (orange - oxygen mass) and simulated (blue - oxygen mass)

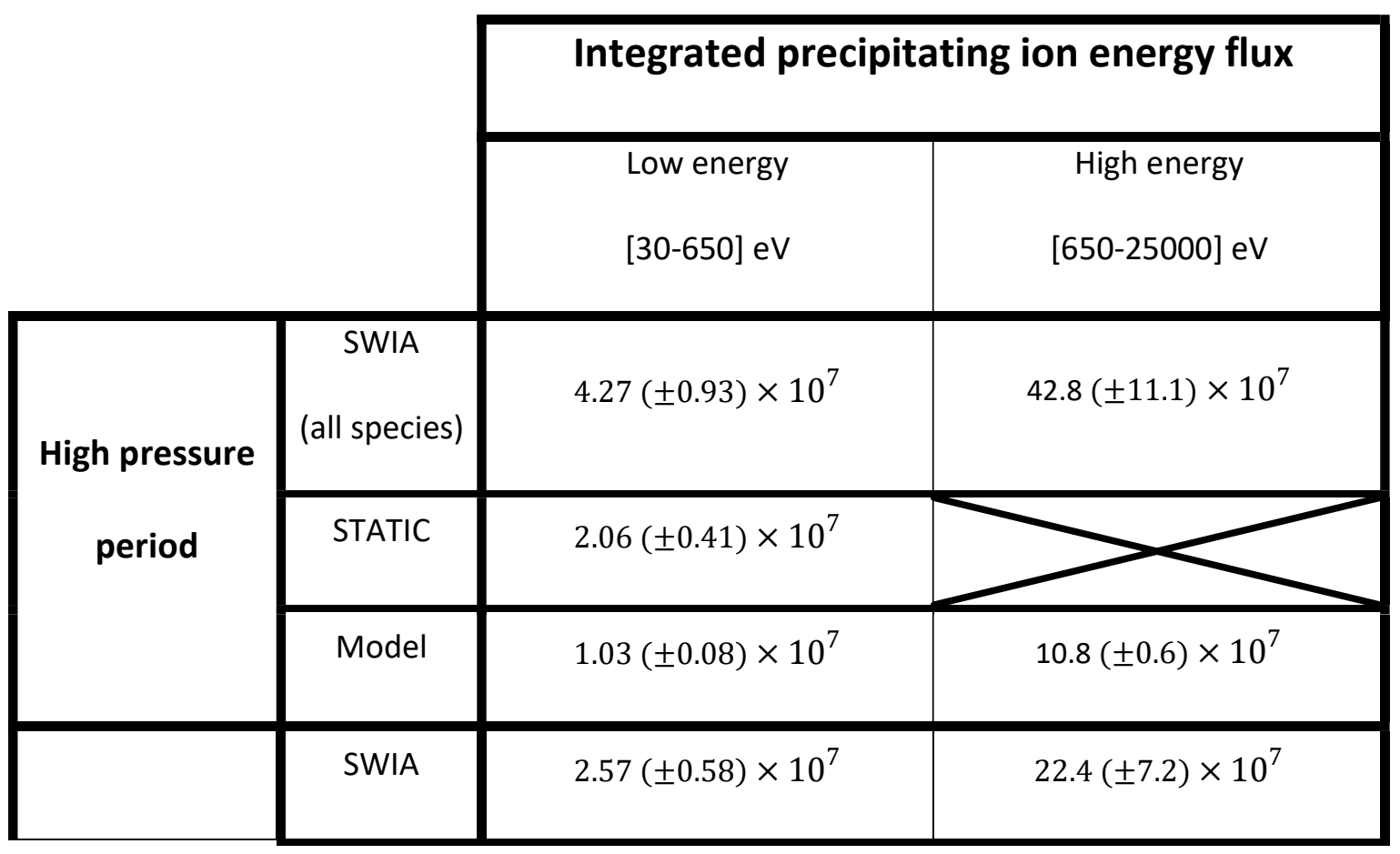




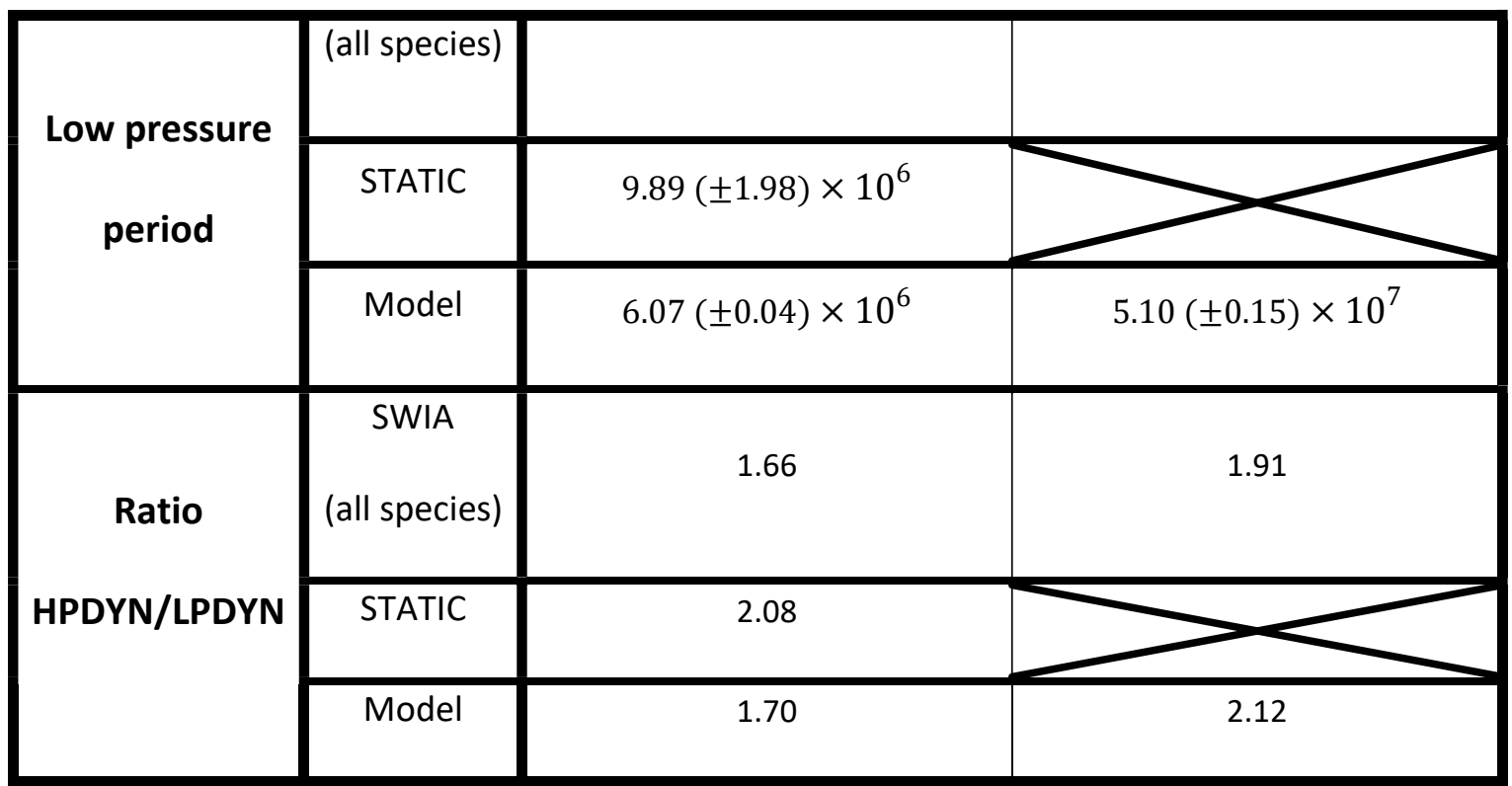

Table 2: Integrated precipitating ion energy flux as measured by MAVEN/STATIC (only oxygen ion) and MAVEN/SWIA (all species) and modelled by LatHyS (only oxygen ion) for each period. The last three line correspond to the ratio between the high pressure period values and the low pressure period values for each instrument. In brackets, the 1-sigma standard deviation (uncertainty) of the precipitating ion energy flux values. The integrated ion precipitation unit is in $\mathrm{eV} . \mathrm{cm}^{-2} . \mathrm{sr}^{-1} . \mathrm{s}^{-1}$.

\section{B. Origins and parameters controlling the simulated precipitating fluxes}

Figure 2 displays the impact energy of the precipitating oxygen ions (of ionospheric origin, created by photo-ionization or by charge exchange) as a function of their injection (creation) position in the $(\mathrm{X}, \rho)$ coordinate system with $\rho=\sqrt{Y^{2}+Z^{2}}$, for the low pressure case. The negative values of $\rho$ correspond to the Southern Hemisphere MSE $(Z<0)$ while positive values indicate the Northern Hemisphere $(Z>0)$. The lack of injected particles behind Mars is explained by the shadow of the planet, preventing photo-ionizations. The precipitating ions with energy higher than the solar wind $(800 \mathrm{eV}$ $1 \mathrm{keV}$ ) are formed in the southern hemisphere MSE and their final energy depends on their altitude of creation (by ionization). This energy-altitude injection relation is consistent with Jarvinen et al. (2018) and can be explained by the time spent by an ion in the high electric field regions (essentially the solar wind and the magnetosheath). In the northern hemisphere, it can also be seen that precipitating ions are mainly formed within or downstream of the pile-up magnetic region. The high-energy ions 
337 precipitate mainly in the Southern hemisphere and on the Martian dayside (not shown) as simulated

338 in Luhmann and Kozyra (1991). This distribution of the origin position of precipitating ions and their 339 impact energy can be explained by the intensity of the electric field and its direction (Chaufray et al., 340 2007; Curry et al., 2015). In the upstream solar wind and the magnetosheath, the newly born ions will 341 be accelerated in the direction of the convective electric field. Ions formed in the northern hemisphere 342 MSE will be moved away Mars, while ions formed in the southern hemisphere MSE will be accelerated 343 toward Mars, as observed in Hara et al. (2017a). This is why for high $\mathrm{X}>0$ and $\rho>-0.5$ in Figure 2, 344 there are almost no precipitating ions formed upstream the bow shock. The ions formed inside the 345 magnetosheath will see a disturbed electric field direction which may lead them to precipitate. To 346 summarize, this result indicates that oxygen ions created above the ionosphere in the $-E$ hemisphere

347 can more easily precipitate toward the planet rather than those created in the +E hemisphere, in good 348 agreement with previous numerical simulations (Chaufray et al., 2007; Fang et al., 2010; Curry et al., 349 2015). 


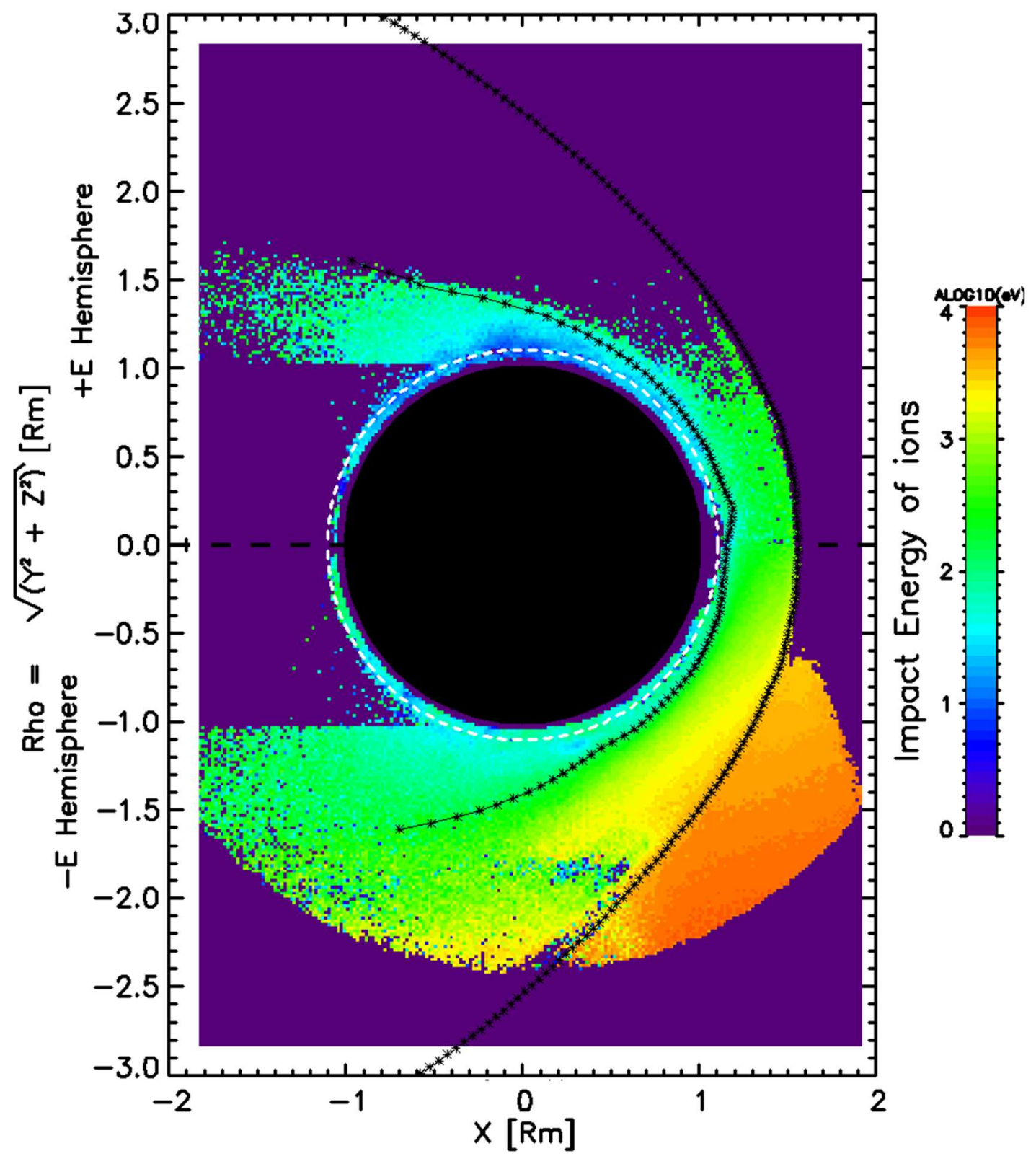

352 Figure 2: Map of the origin position of the precipitating ions produced either in the ionosphere (below

$353350 \mathrm{~km}$ in altitude), by photo-ionization or by charge exchange for the low pressure period. The impact

354 energy of the modelled ions is shown in color. The black lines correspond to the ion magnetopause

355 boundary (closest to Mars) and bow shock (farthest from Mars) location. The dashed white circle

356 corresponds to the upper limit of the ionosphere (350 $\mathrm{km}$ in altitude). 
Figure 3 displays the energy distribution of the simulated precipitating oxygen ion energy flux averaged over the whole oxygen ion precipitation map (without removing the background value of MAVEN/SWIA). In the high dynamic pressure case, the maximum energy of the ions impacting the atmosphere reaches $14 \mathrm{keV}$ whereas in the low dynamic pressure case only $10 \mathrm{keV}$. This illustrates the fact that ions created at the same position see a stronger electric field intensity in the case of high pressure $\left(E=1.44 \mathrm{mV} \cdot \mathrm{m}^{-1}\right.$ upstream of the bow shock) than in the case of the low pressure $(E=$ $1.04 \mathrm{mV} \cdot \mathrm{m}^{-1}$ upstream of the bow shock)

As a matter of fact, the main difference between the two modelled dynamic pressure cases can be described as a global shift in energy, associated with a change in the local electric field intensity, and an increase of the intensity of the precipitating ions. As an example, in the case of the ionospheric ions (red lines in Figure 3), there is a significant increase of the precipitating flux with increasing dynamic pressure above $50 \mathrm{eV}$, as observed by the MAVEN/STATIC. In the same way, in the case of the ions produced by photoionization Figure 3, there is globally an increase in energy of the precipitating ions due to the increase of the electric field close to Mars when increasing the dynamic pressure.

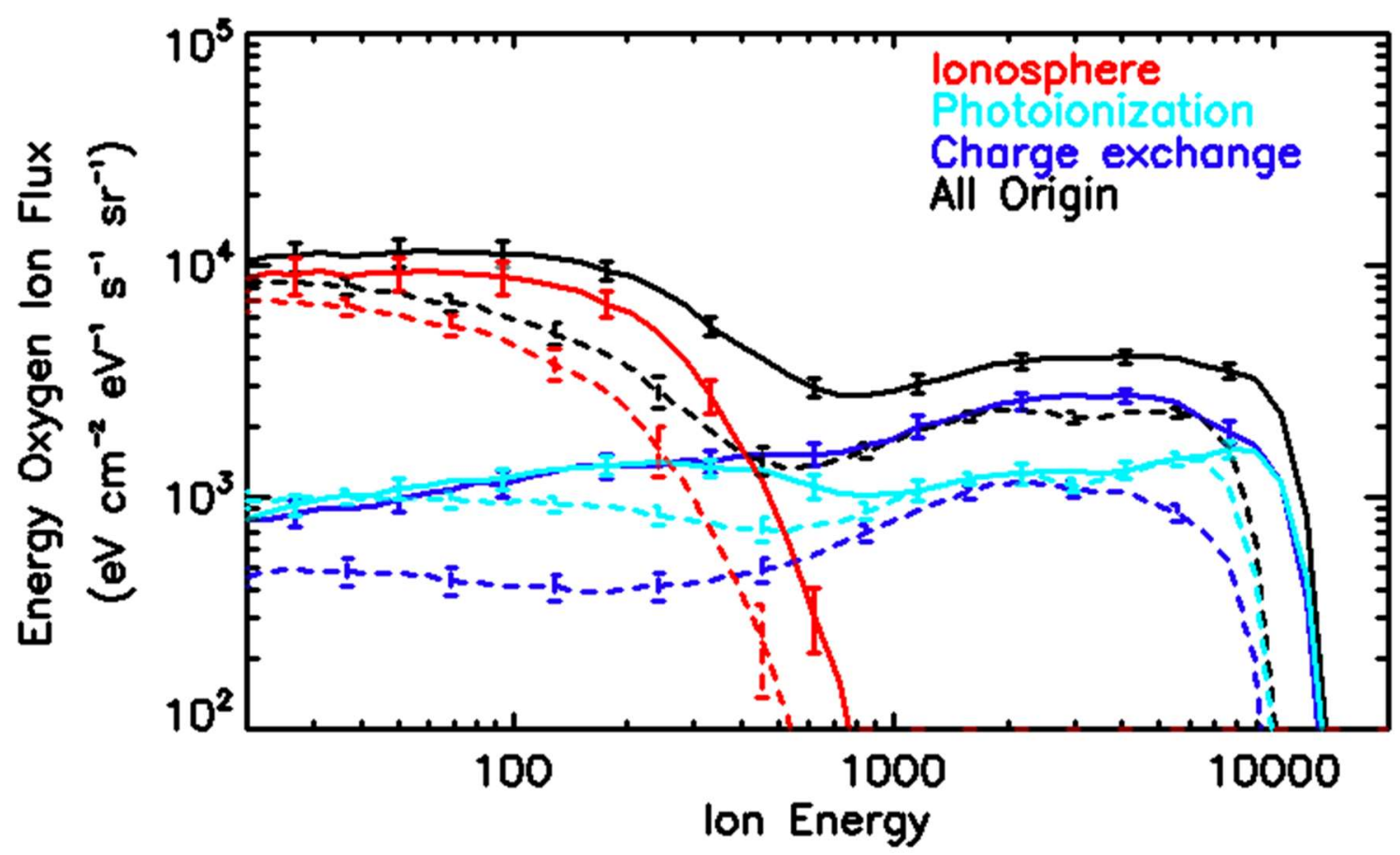

372 
Figure 3: Simulated precipitating oxygen ion differential energy spectra. Solid line: high dynamic pressure case. Dashed line: low dynamic pressure case. Red lines: oxygen ionospheric ions. Dark blue lines: oxygen ions produced by charge exchange. Light blue lines: oxygen ions produced by photoionization. Black lines: total precipitating oxygen ions flux. Vertical lines: standard deviation of the flux estimated by performing several snapshots during the simulation.

However, in the case of the ion produced by charge exchange, a higher dynamic pressure induces not only a gain of energy of the precipitating particle but also an increase in the charge exchange ionization rate between solar wind protons and $\mathrm{O}$ atmospheric neutral particles which should be proportional to the solar wind particle flux $\sim n_{S W} V_{S W}$. The ionization rate by charge exchange should increase by a factor $\sim 2.3$ which is the ratio between the solar wind flux in the high dynamic pressure case to the solar wind flux in the low dynamic pressure case. This ratio is very close to the ratio of the precipitating fluxes of the ions produced by charge exchange between the high and low dynamic pressure cases (equal to 2.7). On the other hand, the production rates of ion in the ionosphere or by photo-ionization are not or only in a limited way influenced by the change of the solar wind dynamic pressure. As shown in Figure 3 in the case of the high dynamic pressure (dark blue line), the precipitating flux is dominated by ions produced by charge exchange above $1 \mathrm{keV}$. In the low dynamic pressure case, charge exchange and photo-ionization produces roughly the same amount of ions according to the simulation.

The main lessons from the simulation are:

- An increase of the dynamic pressure should lead to a global increase of the energy of the ion precipitating in the atmosphere, roughly proportionally with the change of the motional electric field in the undisturbed solar wind.

- An increase of the dynamic pressure should lead to an increase of the charge exchange rate in a proportion roughly equivalent to the increase in solar wind flux. This effect should be observable at high energy, above typically $1 \mathrm{keV}$, where the contribution of 

the charge exchange mechanism on the production of the precipitating ion starts to dominate.

- Below $1 \mathrm{keV}$, the precipitating ion energy flux should be dominated by the ionospheric ions which are poorly described by LatHyS due to a limitation in spatial resolution.

402

403

404

405

We also evaluated the impact of the dynamic pressure on the plasma boundaries (essentially on the bow shock position) by comparing the precipitating flux of oxygen ions produced by photo-ionization upstream of the bow shock for both cases. With a small difference between the two cases, we concluded that the precipitating ion flux is only weakly influenced by the compression of the bow shock with increasing solar dynamic pressure (see supplementary document).

\section{Summary and Conclusion}

Solar wind observations around Mars from the MAVEN spacecraft from 04 June 2015 to 20 July 2017 are organized into two sets of measurements corresponding to two periods of significantly different solar dynamic pressure. Beside different solar wind conditions, all other parameters that could potentially influence the state of Mars' atmosphere and magnetosphere are carefully estimated in order to be equivalent in both samples (by selecting only observations with the same solar conditions and geographic coverage). From these two periods, we then use MAVEN portions of orbit between 350 and $200 \mathrm{~km}$ in altitude to reconstruct the precipitating ion energy fluxes from SWIA (Halekas et al. 2015) and STATIC (McFadden et al. 2015) measurements following the method developed in Leblanc et al. (2015) and Martinez et al. (2019a).

The average solar conditions of each period are then used to simulate Mars' environment using LatHyS hybrid model (Modolo et al. 2016). These two simulations are realized for the same solar extreme ultra-violet conditions, the same season of the Martian atmosphere $\left(L S=270^{\circ}\right)$, with the same orientation of the Interplanetary Magnetic Field and the main crustal field placed in the nightside. A 
method is also developed in order to reconstruct the oxygen ion precipitation from both simulations using the same approach as when analyzing MAVEN measurements.

The precipitating ion energy flux measured by MAVEN/STATIC and MAVEN/SWIA increases with the increase of the solar wind dynamic pressure, which is consistent with previous studies (Hara et al., 2017a). The increase of the dynamic pressure from 0.63 to $1.44 \mathrm{nPa}$ is clearly associated with an increase at the same order of the precipitating oxygen ion energy flux measured by MAVEN/STATIC from 9.9 to $20.6 \times 10^{6} \mathrm{eV} . \mathrm{cm}^{-2} . \mathrm{sr}^{-1} . \mathrm{s}^{-1}$ (a ratio of $~ 2.1$ ) for the low energy range (from 30 to 650 eV). From $650 \mathrm{eV}$ to $25000 \mathrm{eV}$, observations by MAVEN/SWIA show an increase from 22.4 to $42.8 \times$ $10^{7} \mathrm{eV} \cdot \mathrm{cm}^{-2} \cdot \mathrm{sr}^{-1} \cdot \mathrm{s}^{-1}$ (a ratio of $~ 1.9$ ) with a similar order as the increase in solar wind dynamic pressure.

Such increase can be explained, according to the simulation results by several mechanisms. The increase of the dynamic pressure leads to a global increase of the energy and intensity of the ion precipitating into the atmosphere. In terms of energy differential precipitating flux, this is equivalent to a shift in energy of the flux proportional to the increase of the solar wind convective electric field intensity upstream to Mars, and an increase of the intensity of the energy differential precipitating flux, proportional to the increase of the solar wind flux because an increase of the solar wind flux also implies a change of the charge exchange rate between the incident solar wind ions and the planetary exosphere. Such effect is particularly observable above $1 \mathrm{keV}$ in the simulated precipitating ion energy flux where the flux is in a large proportion composed of planetary oxygen ions formed by charge exchange.

\section{Acknowledgements}

This work was supported by the DIM ACAV and the ESA/ESTEC faculty. This work was also supported by CNES "Système Solaire" program and by the "Programme National de Planétologie" and "Programme National Soleil-Terre". This work is also part of HELIOSARES Project supported by the ANR 
(ANR-09-BLAN-0223), ANR MARMITE (ANR-13-BS05-0012-02) and ANR TEMPETE (ANR-17-CE31-0016). Spacecraft data used in this paper are archived and available in the Planetary Data System Archive (https://pds.nasa.gov/). Numerical simulation results used in this article can be found in the simulation database (http://impex.latmos.ipsl.fr).

\section{References}

Acuña, M. H., et al. (1999), Global distribution of crustal magnetization discovered by the Mars Global Surveyor MAG/ER Experiment, Science, 284, 790-793, doi:10.1126/science.284.5415.790.

Anderson D.E and C.W. Hord, Multidimensional radiative transfer: Applications to planetary coronae, Planetary and Space Science, Volume 25, Issue 6, 1977, Pages 563-571, ISSN 0032-0633, https://doi.org/10.1016/0032-0633(77)90063-0.

Andersson, L., R. E. Ergun, and A. I. F. Stewart (2010), The Combined Atmospheric Photochemistry and Ion Tracing code: reproducing the Viking Lander results and initial outflow results, Icarus, 206(1), 120129, https://doi.org/10.1016/i.icarus.2009.07.009.

Barabash, S., Lundin, R., Andersson, H. et al. (2006), The analyzer of space plasmas and energetic atoms (ASPERA-3) for the Mars Express mission, Space. Sci. Rev., 126, 113-164, https://doi.org/10.1007/s11214-006-9124-8

Brain, D. A., F. Bagenal, Y.-J. Ma, H. Nilsson, and G. Stenberg Wieser (2016), Atmospheric escape from unmagnetized bodies, J. Geophys. Res. Planets, 121, 2364-2385, doi:10.1002/2016JE005162.

Chassefière, E., and F., Leblanc (2004), Mars atmospheric escape and evolution; interaction with the solar wind, Planet. Space Sci., 52, 1039-1058, doi: 10.1016/j.pss.2004.07.002 
Chaufray, J. Y., R. Modolo, F. Leblanc, G. Chanteur, R. E. Johnson, and J. G. Luhmann (2007), Mars solar wind interaction: Formation of the Martian corona and atmospheric loss to space, J. Geophys. Res., 112, E09009, doi:10.1029/2007JE002915.

Chaufray, J.-Y., Gonzalez-Galindo, F., Forget, F., Lopez-Valverde, M., Leblanc, F., Modolo, R., Hess, S., Yagi, M., Blelly, P.-L., and Witasse, O. (2014), Three-dimensional Martian ionosphere model: II. Effect of transport processes due to pressure gradients, J. Geophys. Res. Planets, 119, 1614- 1636, doi:10.1002/2013JE004551.

Chicarro, A., P. Martin, and R. Trautner (2004), The Mars Express mission: An overview, in Mars Express: A European Mission to the Red Planet, Eur. Space Agency Spec. Publ., ESA SP-1240, edited by A. Wilson and A. Chicarro, pp. 3-16, ESA Publ. Div., ESTEC, Noordwijk, Netherlands.

Connerney, J.E.P., Espley, J., Lawton, P. et al., The MAVEN Magnetic Field Investigation, Space Sci Rev (2015a) 195 : 257., https://doi.org/10.1007/s11214-015-0169-4

Connerney, J.E.P., Espley, J.R., DiBraccio, G.A., et. al. (2015b). First results of the MAVEN magnetic field investigation. Geophys. Res. Lett., 42, 8819-8827, doi:10.1002/2015GL065366.

Curry S. M., Luhmann J. G., and al. (2015), Response of Mars 0+ pickup ions to the 8 March 2015 ICME: Inferences from MAVEN data-based models., Geophys. Res. Lett, 42, 9095-9102, doi:10.1002/2015GL06304.

Diéval, C., et al. (2012), A case study of proton precipitation at Mars: Mars Express observations and hybrid simulations, J. Geophys. Res., 117, A06222, doi:10.1029/2012JA017537.

Dong, Y., Fang, X., Brain, D. A., McFadden, J. P., Halekas, J. S., Connerney, J. E. P., Eparvier, F., Andersson, L., Mitchell, D., and Jakosky, B. M. (2017), Seasonal variability of Martian ion escape through the plume and tail from MAVEN observations, J. Geophys. Res. Space Physics, 122, 4009-4022, doi:10.1002/2016JA023517. 
Edberg, N., Brain, D. A., Lester, M., Cowley, S. W. H., Modolo, R., Franz, M., and Barabash S. (2009), "Plasmas boundary variability at Mars as observed by Mars Global Surveyor and Mars Express », Ann. Geophys., 27, 3537-3550, doi:10.5194/angeo-27-3537-2009.

Edberg, N. J. T., Lester, M., Cowley, S. W. H., Brain, D. A., Fränz, M., and Barabash, S. (2010), Magnetosonic Mach number effect of the position of the bow shock at Mars in comparison to Venus, J. Geophys. Res., 115, A07203, doi:10.1029/2009JA014998.

Eparvier, F.G., Chamberlin, P.C., Woods, T.N. et al., The Solar Extreme Ultraviolet Monitor for MAVEN, Space Sci Rev (2015) 195 : 293., https://doi.org/10.1007/s11214-015-0195-2

Fang, X., Liemohn, M. W., Nagy, A. F., Luhmann, J. G., and Ma, Y. (2010), Escape probability of Martian atmospheric ions: Controlling effects of the electromagnetic fields, J. Geophys. Res., 115, A04308, doi:10.1029/2009JA014929.

Fang, X., S. W. Bougher, R. E. Johnson, J. G. Luhmann, Y. Ma, Y.-C. Wang, and M. W. Liemohn (2013), The importance of pickup oxygen ion precipitation to the Mars upper atmosphere under extreme solar wind conditions, Geophys. Res. Lett., 40, 1922-1927, doi:10.1002/grl.50415.

Forget, F., Hourdin, F., Fournier, R., Hourdin, C., Talagrand, O., Collins, M., ... Huot, J.-P. (1999). Improved general circulation models of the Martian atmosphere from the surface to above $80 \mathrm{~km}$. Journal of Geophysical Research, 104(E10), 24,155-24,175. https://doi.org/10.1029/1999JE001025

Fedorov A., Budnik E., Sauvaud J.-A., Mazelle C., Barabash S., Lundin R., Acuña M., Holmström M., Grigoriev A., Yamauchi A., Andersson H., Thocaven J.-J., Winningham D., Frahm R., Sharber J.R., Scherrer J., Coates A.J., Linder D.R., Kataria D.O., Kallio E., Koskinen H., Säles T., Riihelä P., Schmidt W., Kozyra J., Luhmann J., Roelof E., Williams D., Livi S., Curtis C.C., Hsieh K.C., Sandel B.R., Grande M., Carter M., McKenna-Lawler S., Orsini S., Cerulli-Irelli S., Maggi M., Wurz P., Bochsler P., Krupp N., Woch J., Fränz M., Asamura K., Dierker C., Structure of the Martian wake, Icarus, Volume 182, Issue 2, 2006, Pages 329-336, ISSN 0019-1035, https://doi.org/10.1016/i.icarus.2005.09.021. 
Fox, J.. (2004). Response of the Martian thermosphere/ionosphere to enhanced fluxes of solar soft X rays. Journal of Geophysical Research. 109. Doi:10.1029/2004JA010380.

Halekas, J.S., Taylor, E.R., Dalton, G. et al., The Solar Wind Ion Analyzer for MAVEN, Space Sci Rev (2015) 195 : 125., https://doi.org/10.1007/s11214-013-0029-z

Halekas, J. S., et al. (2017), Structure, dynamics, and seasonal variability of the Mars-solar wind interaction: MAVEN Solar Wind Ion Analyzer in-flight performance and science results, J. Geophys. Res. Space Physics, 122, 547-578, doi: 10.1002/2016JA023167.

Hall, B. E. S., et al. (2016), Annual variations in the Martian bow shock location as observed by the Mars Express mission, J. Geophys. Res. Space Physics, 121, 11,474- 11,494, doi:10.1002/2016JA023316.

Hara, T., K. Seki, Y. Futaana, M. Yamauchi, M. Yagi, Y. Matsumoto, M. Tokumaru, A. Fedorov, and S. Barabash (2011), Heavy-ion flux enhancement in the vicinity of the Martian lonosphere during CIR passage: Mars Express ASPERA-3 observations, Journal of Geophysical Research, vol. 116, A02309, doi:10.1029/2010JA015778, 2011.

Hara, T., et al. (2017a), MAVEN observations on a hemispheric asymmetry of precipitating ions toward the Martian upper atmosphere according to the upstream solar wind electric field, J. Geophys. Res. Space Physics, 122, 1083-1101, doi: 10.1002/2016JA023348

Hara T. et al., (2017b), Evidence for crustal magnetic field control of ions precipitating into the upper atmosphere of Mars, J. Geophys. Res. Space Physics, 122, doi: 10.1029/2017JA024798.

Jakosky, B.M., Lin, R.P., Grebowsky, J.M. et al., The Mars Atmosphere and Volatile Evolution (MAVEN) Mission, Space Sci Rev (2015) 195 : 3. https://doi.org/10.1007/s11214-015-0139-x Jarvinen, R., and Kallio, E. (2014), Energization of planetary pickup ions in the solar system, J. Geophys. Res. Planets, 119, 219- 236, doi:10.1002/2013JE004534. 
Jarvinen, R., Brain, D. A., Modolo, R., Fedorov, A., \& Holmström, M. (2018). Oxygen ion energization at Mars: Comparison of MAVEN and Mars express observations to global hybrid simulation. Journal of geophysical research: Space physics, 123(2), 1678-1689. https://doi.org/10.1002/2017JA024884

Johnson, R.E., Plasma-induced sputtering of an atmosphere, Space Sci Rev (1994) 69: 215. https://doi.org/10.1007/BF02101697

Johnson, R. E., D. Schnellenberger, and M. C. Wong (2000), The sputtering of an oxygen thermosphere by energetic $\mathrm{O}^{+}$, J. Geophys. Res., 105(E1), 1659-1670, doi:10.1029/1999JE001058.

Krasnopolsky, V. A., and P. D. Feldman (2001). Detection of molecular hydrogen in the atmosphere of Mars. Science, 294,1914- 1917.

Leblanc, F. and R.E Johnson, Sputtering of the Martian atmosphere by solar wind pick-up ions, Planet. Space Sci., 49, 645-656, 2001, doi:10.1016/S0032-0633(01)00003-4.

Leblanc F. and R.E. Johnson (2002), Role of molecules in pick-up ion sputtering of the Martian atmosphere, J. Geophys. Res., https://doi.org/10.1029/2000JE001473

Leblanc F., R. Modolo and al. (2015), Mars heavy ion precipitating flux as measured by Mars Atmosphere and Volatile EvolutioN, Geophys. Res. Lett, 42, 9135-9141, doi: 10.1002/2015GL066170.

Leblanc, F., Chaufray, J. Y., Modolo, R., Leclercq, L., Curry, S., Luhmann, J., ... Jakosky, B. (2017). On the origins of Mars' exospheric nonthermal oxygen component as observed by MAVEN and modeled by HELIOSARES. Journal of Geophysical Research: Planets, 122, 2401-2428.

\section{https://doi.org/10.1002/2017JE005336}

Lillis, R.J., Brain, D.A., Bougher, S.W. et al., Characterizing Atmospheric Escape from Mars Today and Through Time, with MAVEN, Space Sci Rev (2015) 195: 357. https://doi.org/10.1007/s11214-015-0165- 
Lillis, R. J., et al. (2017), Photochemical escape of oxygen from Mars: First results from MAVEN in situ data, J. Geophys. Res. Space Physics, 122, 3815- 3836, doi:10.1002/2016JA023525.

Luhmann, J. G. (1990), A model of the ion wake of Mars, Geophysical Research Letters, 17, 869-872, https://doi.org/10.1029/GL017i006p00869

Luhmann, J. G., and J. U. Kozyra (1991), Dayside pick-up oxygen ion precipitation at Venus and Mars: Spatial distributions, energy deposition and consequences, J. Geophys. Res., 96(A4), 5457-5467, doi: 10.1029/90JA01753.

Luhmann, J. G., R. E. Johnson, M. H. G. Zhang, Evolutionary impact of sputtering of the Martian atmosphere by $\mathrm{O}^{+}$pickup ions, Geophys. Res. Lett., 19, 2151-2154, 1992. https://doi.org/10.1029/92GL02485

Lundin, R., A. Zakharov, R. Pellinen, et al. (1990), ASPERA/ Phobos measurements of the ion outflow from the Martian ionosphere, Geophysical Research Letters, 17, 873-876, https://doi.org/10.1029/GL017i006p00873

Lundin, R., Barabash, S., Fedorov, A., Holmström, M., Nilsson, H., Sauvaud, J.-A., \& Yamauchi, M. (2008), Solar forcing and planetary ion escape from Mars, Geophysical Research Letters, 35, L09203, doi: 10.1029/2007GL032884.

Martinez, A., Leblanc, F., Chaufray, J. Y., Modolo, R., Romanelli, N., Curry, S., et al (2019a). Variability of precipitating ion fluxes during the September 2017 event at Mars. Journal of Geophysical Research: Space Physics, 124. https://doi.org/10.1029/2018JA026123

Martinez, A., Leblanc, F., Chaufray, J. Y., Modolo, R., Witasse, O., Dong, Y., et al. (2019b). Influence of extreme ultraviolet irradiance variations on the precipitating ion flux from MAVEN observations. Geophysical Research Letters, 46. https://doi.org/10.1029/2019GL083595

Masunaga, K., et al. (2017), Statistical analysis of the reflection of incident $\mathrm{O}^{+}$pickup ions at Mars: MAVEN observations, J. Geophys. Res. Space Physics, 122, 4089-4101, doi:10.1002/2016JA023516. 
Modolo R., G. M. Chanteur, E. Dubinin and A. P. Matthews (2005), Influence of the solar EUV flux on the Martian plasma environment, Ann. Geophys., 23, 433-444, doi:10.5194/angeo-23-433-2005.

Modolo, R., et al. (2016), Mars-solar wind interaction: LatHyS, an improved parallel 3-D multispecies hybrid model, J. Geophys. Res. Space Physics, 121, 6378-6399, doi: 10.1002/2015JA022324.

Ramstad, R., S. Barabash, F. Yoshifumi, and M. Holmström (2017), Solar wind- and EUV-dependent models for the shapes of the Martian plasma boundaries based on Mars Express measurements, J. Geophys. Res. Space Physics, 122, 7279-7290, doi:10.1002/2017JA024098.

Rahmati, D. E. Larson, T. E. Cravens et al., MAVEN insights into oxygen pickup ions at Mars, Geophysical Research Letters, 42, 21, (8870-8876), (2015). https://doi.org/10.1002/2015GL065262

Romanelli, N., Modolo, R., Leblanc, F., Chaufray, J.-Y., Martinez, A., Ma, Y., et al. (2018). Responses of the Martian magnetosphere to an interplanetary coronal mass ejection: MAVEN observations and LatHyS results. Geophysical Research Letters, 45, 7891- 7900. https://doi.org/10.1029/2018GL077714

Trotignon, J. G., Mazelle C., Bertucci C., and Acuna M. H. (2006), Martian shock and magnetic pile-up boundary positions and shapes determined from the Phobos 2 and Mars Global Surveyor data sets, Planet. Space Sci., 54, 357-369, doi:10.1016/j.pss.2006.01.003.

Wang, Y.-C., J. G. Luhmann, F. Leblanc, X. Fang, R. E. Johnson, Y. Ma, W.-H. Ip, and L. Li (2014), Modeling of the $\mathrm{O}^{+}$pickup ion sputtering efficiency dependence on solar wind conditions for the Martian atmosphere, J. Geophys. Res. Planets, 119, 93-108, doi: 10.1002/2013JE004413.

Wang, Y.-C., J. G. Luhmann, X. Fang, F. Leblanc, R. E. Johnson, Y. Ma, and W.-H. Ip (2015), Statistical studies on Mars atmospheric sputtering by precipitating pickup $\mathrm{O}^{+}$: Preparation for the MAVEN mission, J. Geophys. Res. Planets, 120, 34-50, doi: 10.1002/2014JE004660

Yagi, M., Leblanc, F., Chaufray, J. Y., Gonzalez-Galindo, F., Hess, S., \& Modolo, R. (2012). Mars exospheric thermal and non-thermal components: Seasonal and local variations. Icarus, 221(2), 682693. https://doi.org/10.1016/j.icarus.2012.07.022 
Figure 1. 


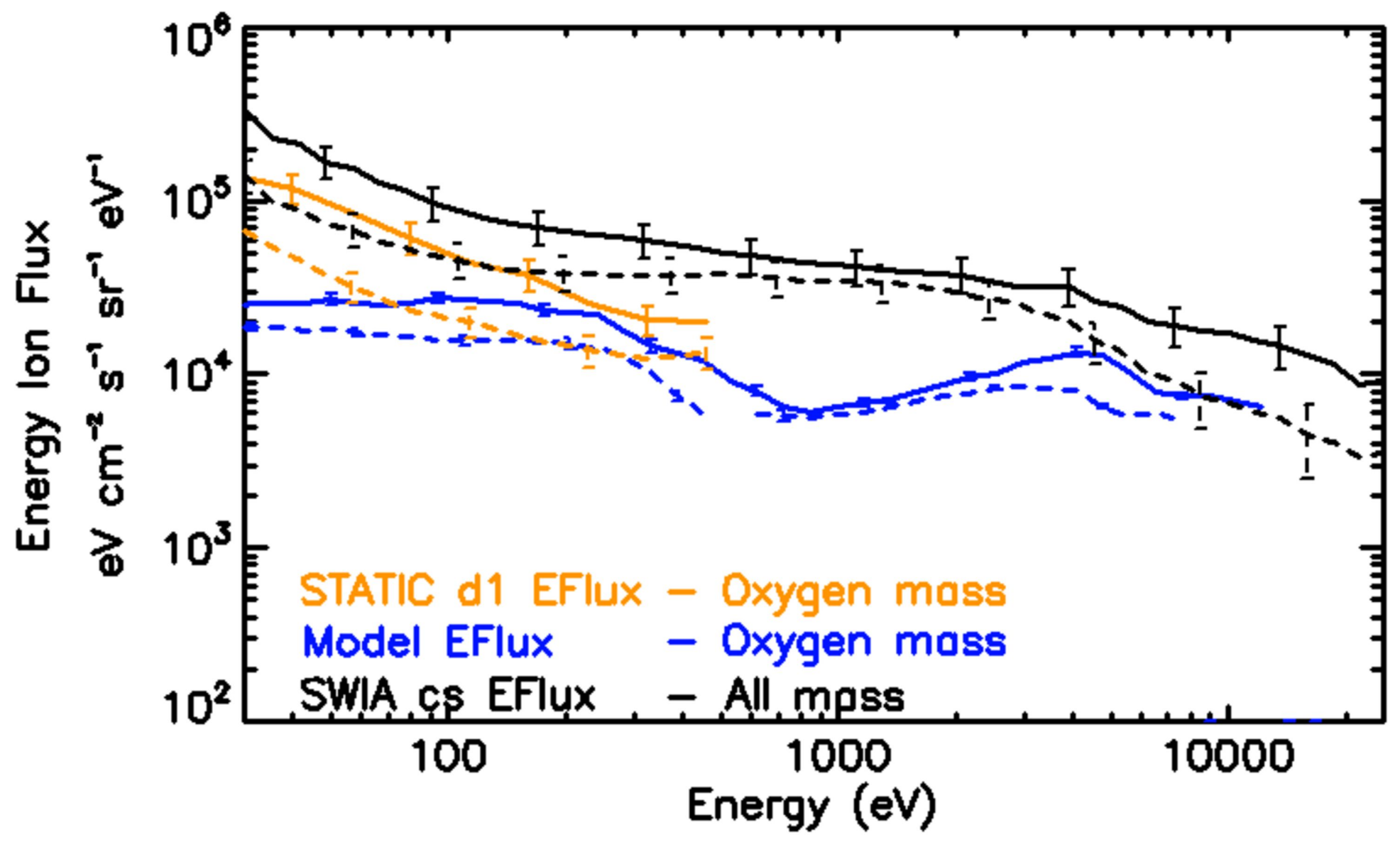


Figure 2. 


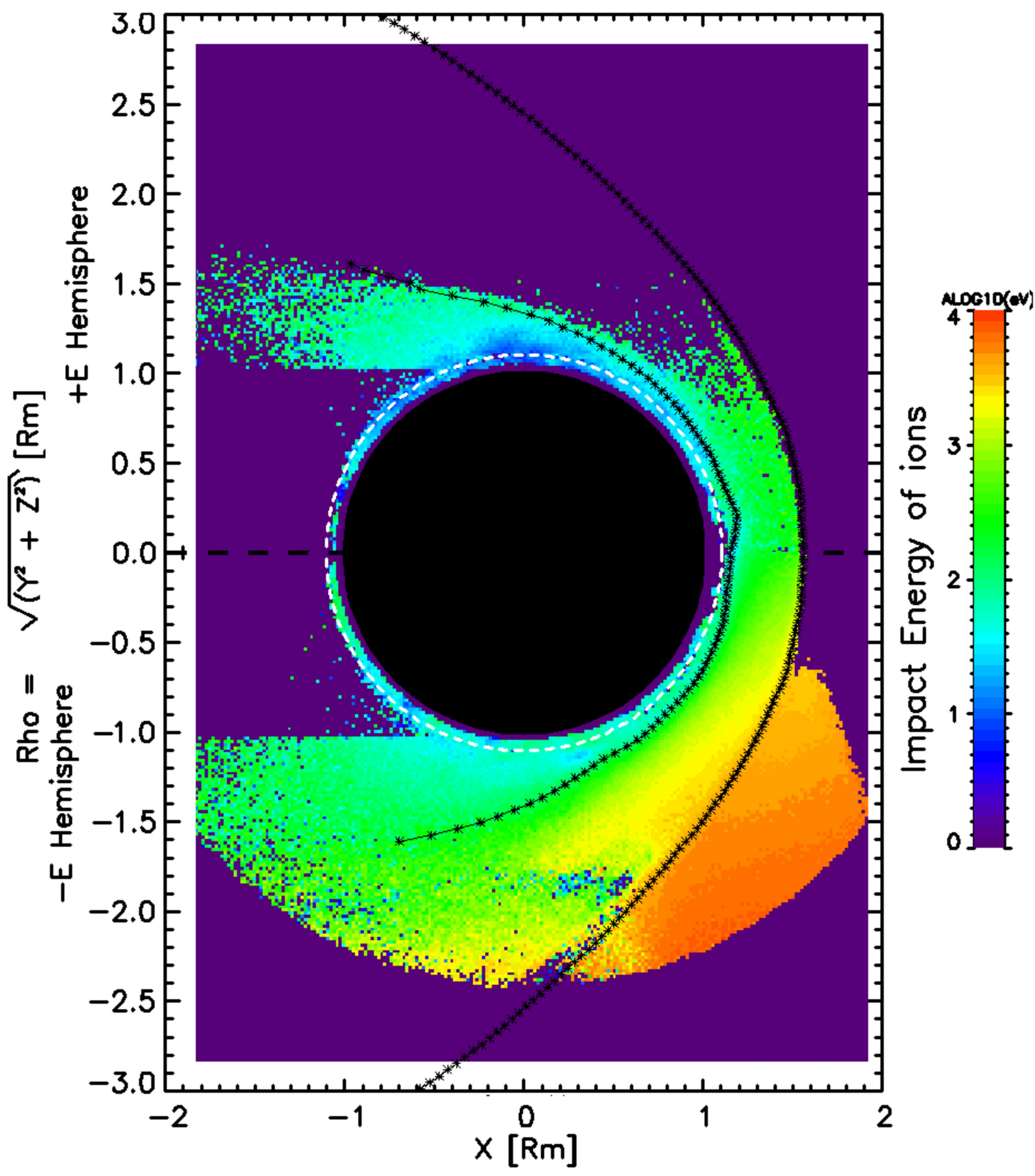


Figure 3. 


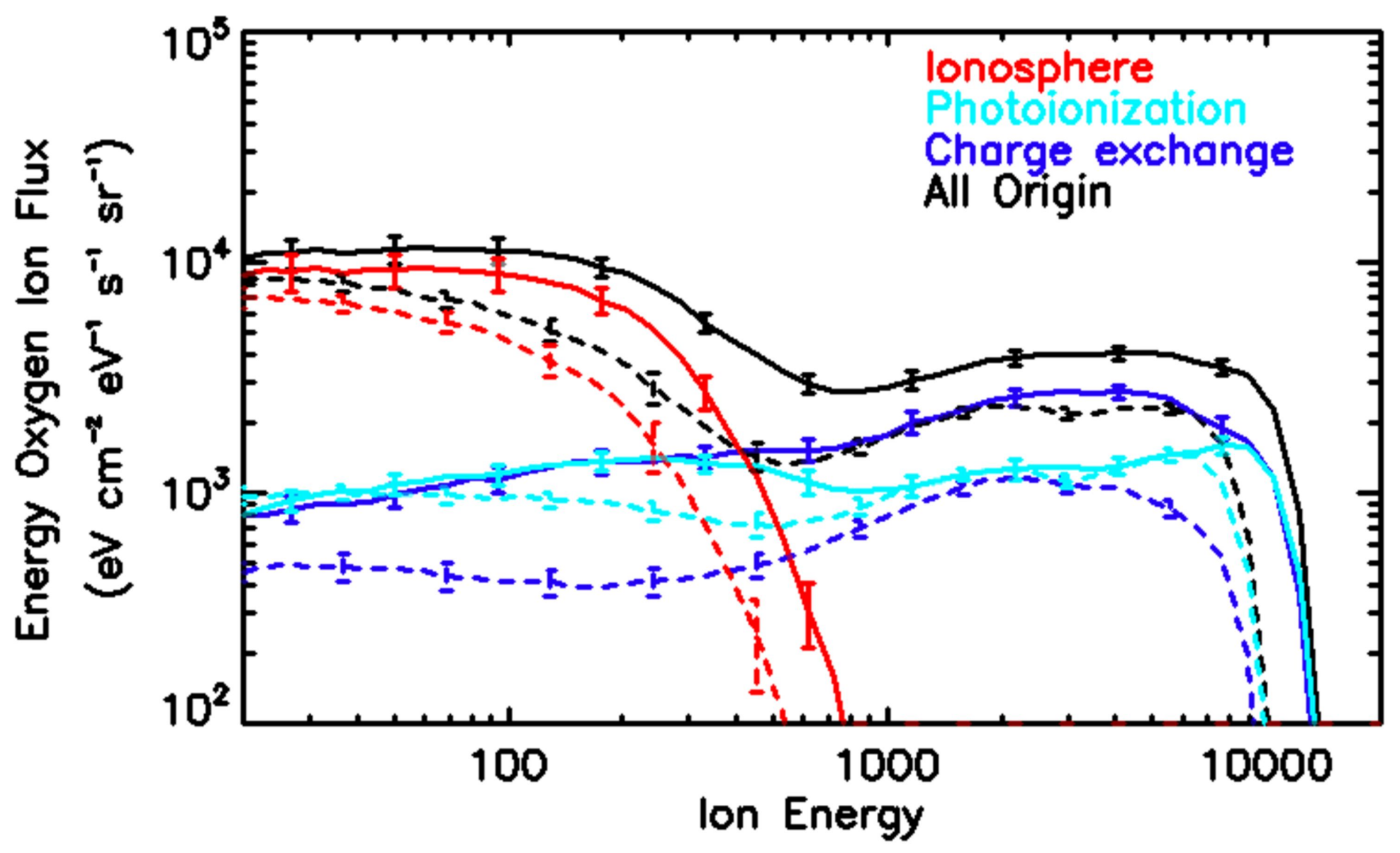

